
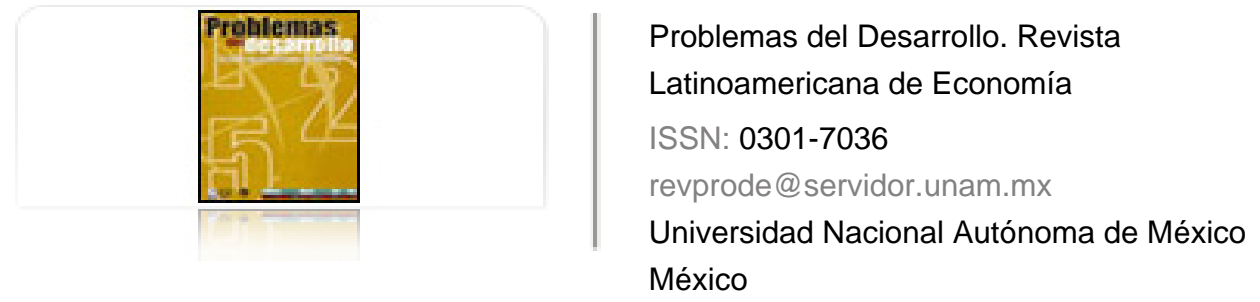

DELGADO RAMOS, GIAN CARLO

La biopiratería y la propiedad intelectual como fundamento del desarrollo biotecnológico

Problemas del Desarrollo. Revista Latinoamericana de Economía, vol. 32, núm. 126, abril-julio, 2001, pp. 175-209

Universidad Nacional Autónoma de México

Distrito Federal, México

Disponible en: http://www.redalyc.org/articulo.oa?id=11820094008

Cómo citar el artículo

- Número completo

- Más información del artículo

Página de la revista en redalyc.org

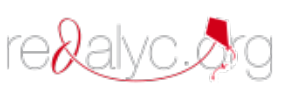

Sistema de Información Científica

Red de Revistas Científicas de América Latina, el Caribe, España y Portugal Proyecto académico sin fines de lucro, desarrollado bajo la iniciativa de acceso abierto 


\section{LA BIOPIRATERÍA Y LA PROPIEDAD INTELECTUAL COMO FUNDAMENTO DEL DESARROLLO BIOTECNOLÓGICO}

GIAN CARLO DELGADO RAMOS*

RESUMEN

El presente artículo se centra en el análisis, desde lo geopolítico y lo geoeconómico, del fundamento estratégico de la biodiversidad, como base del desarrollo de las tecnologías que encabezan la revolución tecnológica de principios del siglo XxI, específicamente en relación con el avance de la biotecnología. En tal sentido, se indaga en los mecanismos impulsados tanto por estados nacionales, como por las grandes firmas involucradas en los bionegocios, para instalar procesos globales de saqueo biótico en las zonas altamente biodiversas (biopiratería), así como en las formas de su apropiación (patentamiento de material genético y su conocimiento tradicional). Tal dinámica es analizada en el nivel mundial y discutida en el caso de México.

Palabras clave: biodiversidad, biopiratería, biotecnología, conocimiento indígena.

\footnotetext{
* Miembro del proyecto DGAPA IN307998 de la Universidad Nacional Autónoma de México (UNAM). Correo electrónico: <giandelgado@hotmail.com>.
} 


\section{Bio-Piracy and Intellectual Property As the Basis of Biotechnological Development}

\section{ABSTRACT}

This article provides a geopolitical and geo-economic analysis of the strategic foundation of biodiversity, as the basis for the development of the technologies that are leading the technological revolution in the early $21^{\text {st }}$ century, specifically in relation to the advance of biotechnology. It explores the mechanisms promoted by both national states and major firms involves in bio-business in order to establish global processes of biotic plundering in highly bio-diverse areas (bio-piracy) as well as the forms of their appropriation (patenting genetic material and their traditional knowledge). This dynamic is analyzed at the world level and discussed with particular reference to Mexico.

Key words: biodiversity, bio-piracy, biotechnology, indigenous knowledge.

\section{BIOPIRATERIE ET PROPRIÉTÉ INTELLECTUELLE, FONDEMENTS DU DÉVELOPPEMENT BIOTECHNOLOGIQUE}

\section{RÉSUMÉ}

L'article présente une analyse des fondements stratégiques de la biodiversité, dans une optique géopolitique et géoéconomique, comme base du développement des technologies pionnières de la révolution technologique de ce début du $\mathrm{XXI}^{\mathrm{e}}$ siècle, tout particulièrement en ce qui concerne les progrès de la biotechnologie. À cet égard, l'auteur examine les mécanismes mis en oeuvre, aussi bien par les États que par les grandes firmes impliquées dans ces marchés de la biotechnologie, pour implanter à l'échelon mondial, des processus de pillage biotique dans des zones à grande biodiversité (biopiraterie), et leurs méthodes d'appropriation (brevetage de matériel génétique et de sa connaissance traditionnelle). Cette dynamique est analysée au niveau mondial et étudiée dans le cas du Mexique.

Mots-clés : biodiversité, biopiraterie, biotechnologie, connaissances autochtones.

\section{PRESENTACión}

ctualmente el desarrollo e innovación tecnológica es impresionante
- prácticamente todos los días se descubre o se perfecciona algo-, de
hecho, ha alcanzado tal grado de maduración que se asegura que 
estamos en un nuevo proceso de revolución tecnológica en el que se identifican cuatro frentes: la electroinformática, los nuevos materiales/nanotecnología, las nuevas energías y la ingeniería genética/biotecnología.

La investigación detrás del presente texto se centra en uno de dichos frentes: la biotecnología. Entendida de la manera más sencilla como la aplicación comercial de técnicas de ingeniería genética, se perfila, hasta ahora, como la más importante dentro de esta nueva revolución, dado el impacto que tiene en una diversidad de ramas productivas e improductivas. Por ejemplo, en la producción de alimentos, medicamentos, plásticos, fibras, aceites, químicos, etcétera, o en la innovación de armas biológicas.

Este artículo da cuenta del proceso de saqueo y apropiación de la biodiversidad debido a que, justamente, las nuevas ciencias que encabezan dicha revolución tecnológica hacen uso de ella. En ese contexto, se muestra la biodiversidad y su conocimiento como riqueza estratégica para el desarrollo capitalista (sobre todo para los capitales vinculados en el desarrollo de la tecnología de punta), de ahí justamente que los capitalistas involucrados se roben esa riqueza y se valgan de mecanismos legales de propiedad intelectual para hacer válida su propiedad privada.

La lógica del ensayo consiste en tres partes. La primera, la conformación de un sistema mundial de bioprospección, que debe verse íntimamente ligada a la segunda parte, la conformación de un sistema mundial de propiedad intelectual. Finalmente, estas dos dinámicas aterrizan en una tercera parte, el estudio de caso de México, donde justamente se pueden identificar las dos dinámicas antes señaladas. Tal esqueleto de razonamiento intenta complejizar las investigaciones afines realizadas antes y al mismo tiempo que ésta, ya que generalmente han perdido de vista o no incluyen la dimensión mundializada de ambos procesos íntimamente relacionados, o bien, el nivel de profundidad de su análisis en algunos casos requiere un mayor detenimiento para su serio estudio.

Independientemente de lo antes indicado, lo que es cierto es que todas las investigaciones, sin ser ésta la excepción, han retomado trabajos previos al mismo tiempo que aportan y refinan - entre otros puntos - la discusión sobre la biopiratería y la propiedad intelectual en México y el mundo. Lo anterior indica que en una u otra medida, la generalidad de las investigaciones dan cuenta de la interconexión entre el desarrollo tecnológico y el espacio físico mundial, así como de la compleja estructura social (valorización, explotación, reproducción, lucha de clases). 
Por ejemplo, cabe señalar que ha sido invaluable el trabajo de la Rural Advancement Foundation International (RAFI) desde la década de los noventa del siglo Xx; aun con su pequeño equipo de trabajo han logrado difundir de manera masiva una cantidad importante de información y de denuncias referentes al desarrollo de las bio-tecnologías. Dicho trabajo, más de carácter activista, es esencial para el análisis profundo que hemos realizado otros investigadores. Aunque hay que precisar que Pat Mooney, presidente de la RAFI, sí ha publicado análisis más complejos que los formidables boletines de esa ONG, tal es el caso de su obra Confinamientos de la razón/Monopolios intelectuales y ETC Century. Sin embargo, aunque son obligadas esas referencias, ambas mantienen aún un relativo límite entre la presentación de datos novedosos y un análisis, en algunos casos, poco profundo pero que sin duda alguna ha sido altamente funcional para crear conciencia e informar a activistas, investigadores o simplemente interesados en la temática (consúltese: <www.rafi.org >).

En el mismo sentido se puede reconocer el trabajo de Genetic Resources Action International (Grain), aunque definitivamente hay que señalar que en lo que se refiere a investigación de campo aún no alcanza las dimensiones y calidad del trabajo de la RAFI, además de que Grain ha restringido su trabajo de difusión más hacia Europa y un poco hacia América del Sur.

En el caso de México se pueden ubicar muchos actores comprometidos en la denuncia de actos de biopiratería, desde aquellos activistas indígenas y campesinos hasta investigadores e intelectuales. Mencionarlos resultaría en un gran listado, sin embargo, por su importancia teórica y metodológica, cabe señalar ahora el trabajo de Andrés Barreda Marín, presidente de la asociación civil Centro de Análisis Social, Información y Formación Popular (Casifop), quien en su tesis doctoral, Atlas geoeconómico y geopolítico del estado de Chiapas, a partir de estudiar el estado de Chiapas, analiza lo que después Vicente Fox denominó como Plan Puebla-Panamá. Tal obra ya incluye los lineamientos y dinámicas de la importancia de la biodiversidad como recurso estratégico clave del nuevo patrón técnico de producción mundial. Barreda Marín - limitado al análisis relativamente genérico de la lógica de la biopiratería en América Latina, específicamente en el sureste de México y parcialmente en Centroamérica, pero insertada en la lógica mundial-, por un lado avanza y desarrolla razonamientos profundos, pero por otro se ve obligado, seguramente por la temática central de su investigación, a dejar de lado la profundización de dinámicas mundiales. Ello lo lleva a perder de vista dos hilos conductores centrales de la indagación acerca de lo estratégico de la biodiversidad, que si bien están presentes de manera dispersa en su análisis, 
nunca son visualizados explícitamente por el autor. Es decir, de manera distinta a Barreda Marín pero retomándolo en gran medida, el eje organizacional del problema lo presento a partir de ver y analizar el proceso mundial de biopiratería y de propiedad intelectual, insertando en ambos hilos conductores el universo de procesos que incluye lo estratégico de la biodiversidad como fundamento del desarrollo biotecnológico.

Lo anterior, permite ver claramente las características, diferencias y dimensiones reales del saqueo y uso de la biodiversidad mundial, pero sobre todo la fuerza con que se viene impulsando dicho proceso y las posibles dimensiones que éste puede tomar si la denuncia por parte de los actores aquí mencionados o ausentes no se hace de manera creciente y organizada. Pero sobre todo, las alternativas propuestas deben corresponder a la dimensión de la realidad, análisis poco profundos nos llevarán a soluciones de esa misma naturaleza, y por lo tanto, no sólo inútiles, sino contraproducentes. En tal sentido, más allá de una crítica positiva al importante trabajo de los actores aquí indicados y que requeriría ser mucho más extensa y detallada, aprovecho el presente artículo para hacer un llamado al trabajo maduro y serio, que busque las alianzas entre los que denunciamos estos procesos de bio-saqueo y que al mismo tiempo deje de lado tanto las críticas negativas, como el ranking de nuestros análisis. Se trata de avanzar como una oposición unida, que basada en el reconocimiento mutuo, logre una alianza verdadera.

\section{INTRODUCCIÓN}

Hoy en día la biodiversidad se ha convertido en una riqueza estratégica a explotar, donde lo estratégico se define a partir de su control. Ello se debe a que los capitales ponen en juego su hegemonía mundial, proceso en el que los capitales contaminantes y los capitales biotecnológicos se ven involucrados en una carrera por controlar esta nueva y singular veta de riqueza (Barreda Marín, 1999). Es decir, se ven envueltos en una carrera por monopolizar la mayor diversidad posible de germoplasma, y por lo tanto en desenfrenada búsqueda, recolección, compra y robo de la diversidad biológica del planeta y de su conocimiento (Delgado, 2000).

Para lograrlo, las altas cúpulas de las grandes corporaciones multinacionales $(\mathrm{CMN})^{1}$ y los estados nacionales centrales (ENC), representantes de la lógi-

1 Uso el término corporaciones multinacionales (CMN) para referirme a las corporaciones de base nacional que operan internacionalmente y que se diferencian de las empresas, que se entenderán como actores con proyección exclusivamente nacional (véase Thompson y Hirst, 2000). Las "transnacionales serían aquellas con un capital genuinamente sin arraigo [footloose (Hirts y 
ca del capitalismo, han diseñado dos líneas de acción por demás complejas. Por un lado, la construcción de un sistema de bioprospección mundial, y por otro, como resultado necesario, el desarrollo de un sistema mundial de propiedad intelectual que penetre las oficinas de patentes nacionales y que permita en un solo movimiento hacer válida la propiedad privada en todo el mundo. Esto último ha redefinido el sistema mundial de derecho internacional público, al inaugurar una nueva especialidad conocida como derecho génico y que se refiere justamente a los lineamientos legales que establezcan un derecho (privado) sobre la vida (Delgado, 2001).

En este contexto, habría que explicitar que la vinculación Estado-Empre$\mathrm{sa} / \mathrm{CMN}$ ha sido y es fundamental, especialmente en la proyección de poder imperial sobre las economías más débiles y sobre las clases vulnerables, tanto de los ENC como los estados nacionales periféricos (ENP). Por ello resulta falsa la creencia de que las CMN se han erigido como un actor autónomo en las relaciones económicas internacionales. Este discurso ofrece una interpretación equívoca, ya que virtualmente todas las CMN del mundo, lejos de ser stateless corporations, operan desde una base nacional, desde un marco de referencia altamente funcional a los intereses privados nacionales, en estrecha relación con un Estado (caso formidable el de Estados Unidos), que las regula y las protege, que las subsidia de diversas maneras, ya sea por medio de un alto gasto público, por la vía de intensas relaciones bélico-industriales o por medio del despliegue de instrumentos de proyección diplomático/militar y/o económico/institucional, como el Banco Mundial, el FMI o el BID.

Thompson)] o stateless (Doremus, 1998), sin una identificación nacional específica y con un cuerpo administrativo internacionalizado y al menos potencialmente capaces de localizarse y relocalizarse en cualquier lugar del globo para obtener las ganancias más altas y seguras. En contraste, las CMN operan desde una madre patria, un Estado-nación, que las regula, las protege internacionalmente y las subvenciona. Ellas representan abrumadoramente la mayoría. Existen muy escasos ejemplos de verdaderas stateless corporations. En otras palabras, las transnacionales no tendrían una base nacional como es el caso de las CMN pero servirían a los mercados globales por medio de operaciones globales. Consecuentemente, éstas a diferencia de las CMN no estarían controladas o constreñidas por las políticas de estados nacionales específicos, estarían fuera de toda regulación a excepción de aquellas normas acordadas a nivel internacional. Así, los gobiernos nacionales no podrían efectivamente adoptar políticas regulatorias específicas, diferentes a aquellas que contrastan con esos estándares, en detrimento de las operaciones de las corporaciones transnacionales dentro de sus fronteras. Así, virtualmente todas las grandes corporaciones internacionales que operan en el mundo, lejos de ser stateless corporations, operan desde una base nacional, desde un marco de referencia altamente funcional a los intereses privados nacionales, en estrecha relación a un Estado (caso formidable de Estados Unidos), que las regula y las protege, que las subsidia de diversas maneras, ya sea por medio de un alto gasto público, por la vía de intensas relaciones bélico-industriales o por medio del despliegue de instrumentos de proyección diplomático/militar y económico/institucional, como el Banco Mundial, el FMI o el BID" (John Saxe-Fernández, 2000). 
No es casual la forma ni el ritmo creciente con que se realizan los contratos de bioprospección en el mundo, ni el empuje por parte de organismos e instituciones nacionales e internacionales como el Departamento de Defensa de Estados Unidos (DdD), la Organización Mundial de Comercio (OMC) o la International Cooperative Biodiversity Group (ICBG) para homogeneizar, subordinar e integrar las principales oficinas de patentes del planeta, a modo de un sistema internacional.

\section{HACIA UN SISTEMA MUNDIAL DE BIOPROSPECCIÓN}

Los proyectos de bioprospección ${ }^{2}$ que permitan explorar e investigar selectivamente la biodiversidad con la finalidad de hallar recursos genéticos y bioquímicos comercialmente valiosos, para luego patentarlos, dependen del conocimiento de las comunidades rurales e indígenas, las que desde el precapitalismo han construido una relación íntima con la naturaleza. A este proceso de apropiación de la biodiversidad y su conocimiento se le conoce como biopiratería.

El término de biopiratería fue ideado en 1993 por Pat Mooney, presidente de la RAFI (ahora ETC Group) y se refiere, en sus propias palabras a "[...] la utilización de los sistemas de propiedad intelectual para legitimar la propiedad y el control exclusivos de conocimientos y recursos biologicos sin reconocimiento, recompensa o protección de las contribuciones de las comunidades indígenas y campesinas, por lo que la bioprospección no se puede ver más que como biopiratería" (Mooney, 1999).

En este sentido, la biopiratería, no sólo como mera conceptualización analítica, sino como concepción política, únicamente se puede entender como mecanismo de enriquecimiento capitalista, de acciones ecocidas y antítesis de la sustentabilidad. Así, mientras la existencia indígena se basa en los cambios ecológicos generados por su relación con la naturaleza, la sociedad capitalista se fundamenta en los cambios económicos de los mercados (de la tasa de ganancia); por lo que no es por casualidad, sino causalidad que el conocimiento de las mencionadas comunidades, basado en el flujo libre y en la posibilidad de esas culturas de vivir como tales, sea un instrumento estratégico para los capitales que rastrean el planeta en busca de sustancias activas y material

2 Generalmente se refiere al rastreo de biodiversidad como parte de investigaciones científicas, pero hoy en día esto se complejiza porque aparecen como parte de las prospecciones petroleras, mineras, proyectos de conservación ecológica y de recuperación cultural-medicinal, etcétera (Delgado, 2001). 
genético, ya que les facilita y reduce el gasto que ello implica. Este panorama en el que las CMN se encuentran en una gran disyuntiva, por un lado necesitan robarse el conocimiento indígena, y por otro lidiar con el proceso de exclusión y exterminio de las culturas y comunidades indígenas del orbe, es una contradicción que se profundiza cada vez más.

Pero yendo más a fondo, la lógica despilfarradora y destructiva de los capitalistas, totalmente irresponsable y que ha caracterizado la historia del capitalismo, ahora enfrenta dos situaciones complejas. Por un lado, la élite capitalista está persiguiendo, por medio de su poder, intereses contradictorios, caso evidente el de los capitales contaminantes y biotecnológicos. ${ }^{3}$ Mientras que por otro, se puede constatar que los capitalistas en su conjunto se ven forzados (en el largo y mediano, pero crecientemente en el corto plazo) a dar salida a la crisis global que han generado, de manera que garanticen, bajo su lógica, su propia existencia; es decir, mediante un proceso irracional y contradictorio, ${ }^{4}$ en el que los atomizados capitalistas o grupos de ellos actúan

3 El patrón técnico social y ecológicamente agresivo de mediados del siglo Xx está siendo relativamente transformado hacia uno menos destructivo, ahorrador de energía y más limpio, dentro de un marco de correlación de fuerzas entre los capitales biotecnológicos - que abiertamente lo vienen impulsando - y los capitales contaminantes - que intentan detenerlo mientras se apoderan y aseguran una posición hegemónica - (Barreda, 1999; Delgado, 2000).

4 Me refiero a las contradicciones internas que han caracterizado y siguen caracterizando al capitalismo, y que si va a dar salida a dicha crisis tendrá que ser bajo esa lógica. Ello no significa que ésa resulte ser la única salida. También está la que la clase proletaria construya, para cuyo caso resulta central conocer y reconocer la forma en la que se mueven las primeras para entonces poder reformular y edificar todo el modelo civilizatorio. En este contexto, es entonces necesario puntualizar la irracionalidad y contrariedad del capitalismo de principios del siglo XXI. Hoy, la sabiduría convencional nos dice que la globalización es una novedad; sin embargo, el capitalismo nace internacionalizándose, o en otras palabras, surge globalizándose desde hace casi cinco siglos. Lo que es cierto es que se ha reconfigurado y complejizado a lo largo de su historia. Recientemente, la "novedosa economía del laissez faire" no es otra cosa que la recuperación de la teoría neoclásica arreglada a las actuales condiciones históricas del capitalismo para redinamizar la acumulación de capital. Proceso que se puede identificar, no por la desaparición del Estado, sino por una reorientación del mismo. Por un lado, son los estados nacionales centrales los que han impulsado y continúan impulsando la desregulación, y por otro, los estados periféricos - hegemonizados por la oligarquía (históricamente ligada a las clases dominantes de los estados nacionales centrales y a las CMN) - han permitido e incluso estimulado las políticas económicas pensadas por el Centro para el Sur. Lo anterior no se debe a una necesidad técnica - por así decirlo - del sistema, sino más bien de una opción política que le da fuerza a la clase capitalista sobre la trabajadora. Ante esto, si tenemos presente que aquélla sólo vive a costa de explotar al trabajador, queda claro que, como lo indica W. Tabb, “[...] lo que le da fuerza es la debilidad ideológica y organizativa de la Izquierda Internacional[...] la lógica del sistema es la misma que desde el siglo XIX, y la necesidad de que la clase trabajadora se una es cada vez mayor y urgente. Es tiempo de una mayor claridad en nuestra crítica de la base trabajadora que se le ha llamado libre mercado, pero que en realidad es poder de clase." (William K. Tabb, 1997.) 
bajo la racionalidad de una inmediata valorización de su capital (Veraza, 1984). Ambos factores, frente a los márgenes bioquímicos del planeta y los límites sociales que se vienen agudizando, sitúan al capitalismo en el dilema de su propia existencia, pero también de la humanidad. Lo anterior resulta indudablemente importante para los sujetos que peleamos por la conciencia, es decir, para los hombres y mujeres revolucionarios, ya que al concretizar nuestra relación con la naturaleza y con el resto de sujetos en el proceso de trabajo, somos la sinergia potencial de resistencia que puede dar vida a una armonía ecológico-social.

En este contexto, que sin duda alude al patrón tecnológico en construcción y que hace uso de la biodiversidad (biotecnología, nanotecnología, nuevos materiales, etc.), es necesario recuperar el conocimiento precapitalista de ese recurso ahora estratégico, proceso desde luego siempre mediado bajo la lógica del capital para que sea redituable (Veraza, 1984).

A partir de esto, se puede entender la lógica de los derechos de autor y de mejoradores de plantas, las patentes, las marcas comerciales, los diseños industriales y los secretos comerciales, como los principales mecanismos que los capitalistas han establecido desde los inicios de la modernidad para controlar las innovaciones tecnológicas y con ello asegurarse las ganancias extraordinarias generadas. Esto se materializa en la construcción de un sistema legal de patentes en el nivel planetario, que en su forma más refinada, y para el caso de la biotecnología, permite a los capitales recuperar, o mejor dicho robar, el conocimiento milenario que aún conservan las comunidades agrícolas e indígenas.

En el mismo tenor se interpreta la Convención sobre Diversidad Biológica (CBD) que entró en vigencia en diciembre de 1993. En ella, se establece que "los estados tienen derechos soberanos sobre sus materiales biológicos, y que dichos recursos ya no están a la libre disposición de otros". No obstante, lejos de ser un esfuerzo multilateral para apoyar la conservación y el uso sustentable de la biodiversidad -idea que está vendiendo la CBD-, claramente promueve el concepto de bilateralismo para su acceso privado. Estos contratos o acuerdos bilaterales, conocidos como acuerdos de bioprospección, consolidan el hecho de que la biodiversidad ya no está a la libre disposición de otros, sino sólo y exclusivamente de algunos. Además, este estatuto nacionali$z a$ las miles de muestras provenientes de la periferia que están contenidas en los bancos de germoplasma y jardines botánicos de los ENC, y por lo tanto las hace patentables a su favor. Por si fuera poco, la CBD también reconoce y alien- 
ta el uso del "conocimiento, las innovaciones y las prácticas de las comunidades indígenas y locales" [Artículo 8(j)].5

\section{El carácter geopolitico de los jardines botánicos y los bancos de germoplasma}

Es de vital importancia diferenciar los canales mediante los cuales las CMN y los ENC vienen controlando la biodiversidad mundial, proceso en el que se pueden apuntar dos tipos de acumulación: in situ (áreas protegidas y regiones aún no protegidas de gran biodiversidad) y ex situ (jardines botánicos y bancos de germoplasma). Espacialmente, $83 \%$ de los recursos bióticos in situ y de su conocimiento se ubica en los ENP, mientras que sólo 17\% está en los ENC. En relación contraria, $75 \%$ de la biodiversidad ex situ se concentra en los ENC y el resto en los ENP (RAFI, 1996b). Con esta última forma de acumulación, los ENC se liberan de limitantes espaciales, políticas, sociales, de interés nacional y de propiedad intelectual. Ello convierte al monopolio ex situ como socialmente expoliador, económicamente injusto y ecológicamente suicida (Bartra, 2000).

\section{Bancos de germoplasma $(\mathrm{BsG})^{6}$}

Los primeros BsG aparecieron dentro del aparato militar de Estados Unidos, y el más grande del mundo es el Instituto de Patología de las Fuerzas Armadas. Fueron los militares quienes comenzaron a investigar y manipular muestras virales y bacteriológicas para el desarrollo de armas. Ante la necesidad de acumular la mayor cantidad de germoplasma por parte de la industria ya no sólo militar, sino también biotecnológica, se crearon los primeros BSG internacionales.

Para llenarlos de manera rápida y creciente, la industria biotecnológica formalizó el proceso mediante la complejización de las patentes al incluir en el trámite el depósito del material biológico, con lo que generó un foco geoeconómico y geopolítico, al convertirlos en espacios de disputa, especulación y renta.

Los BsG son regulados internacionalmente por el tratado de Budapest - administrado por la World Intellectual Property Organization-, y han sido reconocidos oficialmente con el propósito de llevar a cabo los procesos de

\footnotetext{
5 Según la RAFI hasta la fecha no existe un solo caso en el que se haya pagado regalías por bioprospección y conocimiento indígena a dichas comunidades en todo el mundo, <www.rafi.org >.

6 Los bancos de germoplasma son instalaciones que almacenan y conservan la variabilidad genética, representada por células germinales o semillas, disponible para una población particular de organismos. Aunque son importantes, son un pobre reemplazo del mantenimiento de la diversidad genética in situ.
} 
patentes que desde 1981 se concentran en sólo 26 instituciones de 15 países (RAFI, 1996b). Los BsG contienen muestras biológicas obtenidas en el nivel mundial. Mas no causa sorpresa que la abrumadora mayoría de instituciones que preservan estos recursos estén ubicadas en los ENC.

Para subrayar la importancia de los BsG, bastaría con señalar que hoy en día cuentan con más de 6 millones de muestras únicas, de las cuales cerca de 500 mil están en la red de bancos genéticos de la Consultative Group on International Agricultural Research (CGIAR). ${ }^{7}$ De igual manera, el BsG más grande del mundo, el American Type Culture Collection (ATCC), ubicado en Maryland, Estados Unidos, ya en 1992 almacenaba 41\% (17 mil 724 depósitos) de todos los microorganismos depositados con propósitos de procesar patentes (RAFI, 1996b).

\section{Jardines Botánicos (JB)}

De los 1500 JB del mundo, cerca de tres cuartas partes están en los ENC. Mantienen muestras de la gran mayoría de los taxones de los jardines de la periferia. Si bien todos los JB son repositorios de germoplasma, alrededor de la mitad están activos en su conservación mediante la acumulación y reproducción deliberadas de colecciones de un género, especie en particular, u otra aglomeración de taxones útiles para algún propósito en particular - por ejemplo hierbas chinas o flora de la selva, Costa Rica - (RAFI, 1996b).

\begin{tabular}{lcc}
\hline & $\begin{array}{c}\text { Norte, incluyendo } \\
\text { Europa del Este }\end{array}$ & Sur \\
\hline - Número de jardines & $70 \%$ & $30 \%$ \\
- Número de accesiones & $72 \%$ & $28 \%$ \\
- Número de taxones representados & $86 \%$ & $14 \%$ \\
- Colecciones especiales de germoplasma & $80 \%$ & $20 \%$ \\
\hline
\end{tabular}

FUENTE: RAFI (b), "Empresas farmacéuticas hacen ofertas por las colecciones de los jardines botánicos del norte en un intento de eludir la Convención de Biodiversidad”, RAFI, Communiqué, julio-agosto de 1996.

De acuerdo con un estudio del secretario general de la Asociación Internacional de Jardines Botánicos (RAFI, 1996b), 120 JB de los ENC mantienen colecciones

7 Desde 1974 se comenzó a estructurar una red mundial de BsG a través de la International Board for Plant Genetic Resources (Ipgri), que la ha venido impulsando desde la revolución verde hasta nuestros días, con la ayuda del Banco Mundial, bajo la tutela de Estados Unidos. El Ipgri incluye 16 centros de investigación, programas de investigación universitarios, unidades de almacenamiento gubernamentales y el CGIAR. 
conocidas de especies cultivadas para la producción de alimentos, fibra, aceites, etcétera, mientras que otros 170 - también de ENC - tienen colecciones conocidas de especies medicinales y forestales, además de otro tanto que contienen numerosas plantas nativas y colecciones de plantas provenientes de los ENP.

El redescubierto interés de la industria farmacéutica por las colecciones de germoplasma de los JB se acentuó precisamente en un momento en que en el mundo, especialmente en Europa del Este y la antigua Unión Soviética, se están teniendo dificultades para encontrar fondos para mantener adecuadamente las colecciones. Ello ha beneficiado a dicha industria, específicamente la de Estados Unidos, la cual está invirtiendo bajo la condición de tener acceso a tales colecciones.

\section{El papel de las áreas protegidas como fuente de biodiversidad in situ}

La importancia de las áreas naturales protegidas (ANP), aun por encima de la de los JB y los BsG, se debe, de entrada, a que la biodiversidad ex situ pierde la cualidad de unidad que tiene la in situ. Ello pareciera irrelevante para la industria biotecnológica, sin embargo, la biodiversidad in situ contiene implícitamente información central que determina las características de las estructuras moleculares que componen las distintas formas de vida. ${ }^{8}$ Además, su

8 Según estimaciones, existe una posibilidad de $10^{200}$ de que se pueda construir una molécula orgánica en laboratorio. Cada una de ellas, tiene un rango de $10^{128}$ para conformar un compuesto químico, el cual puede o no tener potencial comercial. Con estas estadísticas, los científicos se han especializado en técnicas y desarrollo de equipo que les permitan producir nuevos compuestos potencialmente comerciales o ya existentes pero en mayores cantidades, a partir de bibliotecas de estructuras moleculares. En este contexto, con el avance de la biotecnología en la identificación en tiempo récord de las estructuras moleculares de cualquier muestra analizada, las CMN farmacéuticas y químicas pueden construir compuestos activos a partir de la búsqueda de dicha estructura en distintas partes del planeta - ya sea en otras especies o variedades -, y buscar la mejor fuente para su patentamiento, y en su caso, explotación. Tal es el caso de una sustancia llamada taxol, que es usada como agente anticancerígeno. Primero fue identificada en Madagascar, después la misma estructura molecular fue encontrada en las Filipinas y finalmente en un banco de germoplasma en Inglaterra. Por todo lo anterior, se puede decir que hoy en día el negocio también lo son los bancos de información sobre las estructuras moleculares de las sustancias activas potencialmente comerciales, conocidos como bibliotecas o colecciones de químicos originales (Novel Chemical Libraries). Podemos encontrar involucradas empresas como Array Biopharma (Colorado, Estados Unidos); ComGenex International (California, Estados Unidos), con más de 10 mil estructuras; Diversa (Estados Unidos), vinculada al Instituto Nacional de Salud a través de la Universidad de Georgia; CombiChem Inc. (California, Estados Unidos), vinculada a Dupont; Maxygen Inc. (California, Estados Unidos), vinculada a Glaxo Wellcome y el Affymax Research Institute; Versicor Inc. (Massachusetts, Estados Unidos), vinculada a Sepracor Inc., entre muchas otras. (Cynthia Robbins-Roth, 2000.) 
importancia para dicha industria radica esencialmente, como ya se mencionó, en el conocimiento de las comunidades rurales e indígenas que coinciden espacialmente con las regiones megadiversas del orbe. En los análisis de Conservation International (CI) se proponen 12 centros megadiversos en el planeta, de los cuales nueve también lo son culturalmente. Igualmente, coinciden las 233 ecorregiones planteadas por World Wide Fund for Nature (WwF), de las cuales cerca del $80 \%$ son habitadas por población indígena, al menos la mitad de las tres mil etnias del planeta. Según datos de Toledo, hoy en día existen alrededor de 10 mil ANP en más de 160 países, con una extensión cercana a los 650 millones de hectáreas ( $5 \%$ de la superficie del orbe), pero es de esperarse que entre 12 y $20 \%$ del planeta, actualmente habitado por indígenas, próximamente sea considerado reserva ecológica. En América Latina, al menos $80 \%$ de las áreas protegidas están habitadas por esas culturas (Toledo, 2000).

En este sentido, y dado lo estratégico de este conocimiento, resulta obvia la intencionalidad del reciente cambio de diseño de las ANP, el cual ahora incluye activamente a las comunidades indígenas y campesinas, a diferencia del modelo popularizado y copiado de Estados Unidos (Parque Nacional de Yellowstone), que consideraba, entre otras características, la existencia y protección del área sin gente, pero sobre todo sin su participación. El nuevo modelo permite, por lado, conservar las características centrales de la diversidad in situ, y por otro, abre paso a la privatización de los puntos de megabiodiversidad del mundo, dando las condiciones necesarias para un fácil acceso a ésta y su conocimiento. Desde aquí se puede visualizar cómo es que la mayoría de las ONG, instituciones y organismos internacionales abocados a lo que ellos llaman "la conservación y el desarrollo sustentable", y que están involucrados de una u otra forma en el avance biotecnológico, son más bien pantalla del proceso de explotación de los recursos bióticos planetarios por el capital. Aunque hay excepciones.

Así, los capitalistas involucrados en el desarrollo de la biotecnología, vienen instalando un sistema de biopiratería mundial cada vez más complejo en el que se involucran más y más protagonistas, todos financiados por los grandes capitales del actual patrón tecnológico y del que se viene configurando. Los primeros actores forman parte de una gama que va desde los biopiratas independientes hasta los proyectos de conservación ecológica (base de la pirámide). Después, nos topamos con institutos de investigación, empresas privadas y Organismo no Gubernamentales (ONG), que pueden trabajar en con- 
junto $0^{9}$ o separados. En seguida, veremos, en algunos casos, agentes como los laboratorios privados, que obtienen sustancias activas provenientes de las muestras biológicas entregadas por algún otro intermediario. En otros, podemos identificar a las CMN implicadas en el desarrollo biotecnológico, que al final de la cadena reciben por uno $\mathrm{u}$ otro camino lo que pagaron inicialmente para conservar el medio ambiente, pago concretado en los montos entregados a ONG, como es el caso espectacular de CI por el número de empresas que la apoyan. Estas últimas sólo dejan administrar sus recursos invertidos a los conocedores, o más bien a los autores intelectuales de la biopiratería (Delgado, 2001).

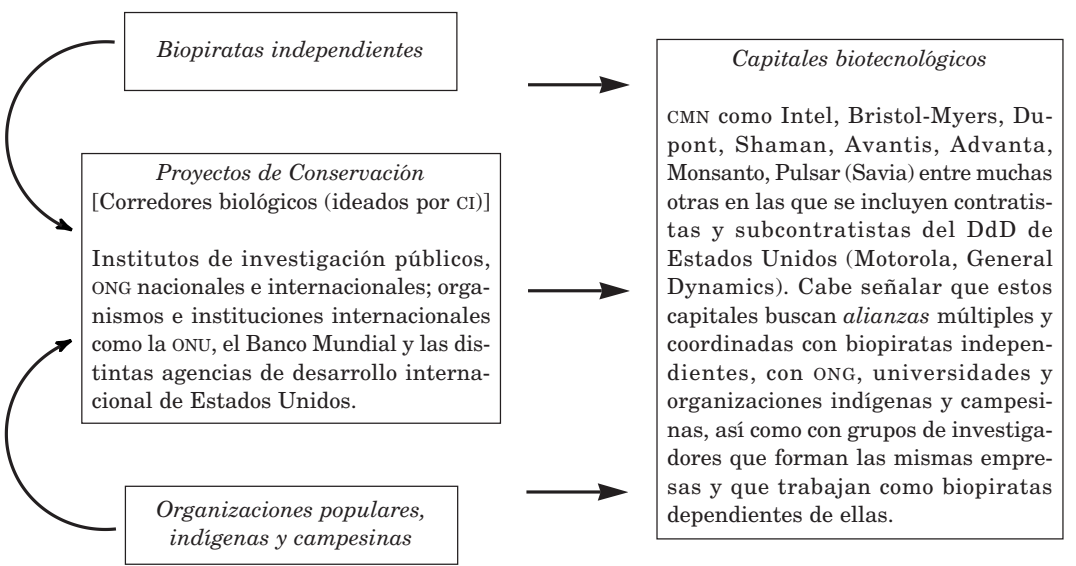

Como puede verse, los nuevos grupos del capital ambientalista (impulsados por el capital biotecnológico), vienen buscando de múltiples maneras una alianza que les permita tener acceso a la biodiversidad y su conocimiento, para hacer uso de ellos y complejizar la creación de la masa y tasa de plusvalía. Pero, dado que el proceso antes descrito no resulta difícil de descifrar, se ha venido promoviendo fuertemente la idea de que la diversidad biológica autopague su conservación.

En México, de las 386 áreas naturales protegidas (7\% del territorio nacional) sólo 123 son responsabilidad de la nación, el resto está en manos de ONG y el capital privado nacional e internacional. Según datos de algunas publica-

9 Caso de CI que ha reclutado ong como la John D. Catherine, T. MacArthur, W. Alton Jones, David and Lucille Packard, Margot Marsho Biodiversity, Alfred Jurzy Kauski, Mulago y Weeden Foundation. Al mismo tiempo trabaja en conjunto con la International Union for the Conservation of Nature (IUCN) y WWF. 
ciones (Castillo, 2000), tal es el caso de Los Ajos, que recibe apoyo del gobierno de Estados Unidos; El Vizcaíno lo apoya el gobierno español y CI, además de CMN como Ford; Montes Azules recibe el apoyo de CI y empresas privadas como Pulsar; Rí Lagarto de Bimbo; Chinchorro de AHMSA; Izta-Popo de Nestlé; El Golfo de California y El Corredor Biológico Mesoamericano del Fondo para el Medio Ambiente Mundial y el Banco Mundial (GEF-BM); La Sierra Gorda del GEF-PNUD (Programa de Naciones Unidas para el Desarrollo); El Triunfo del GEF-BM y Grupo Ecológico Sierra Gorda; Los Tuxtlas, La Chinantla y La Montaña de Guerrero del GEF y PAIR (Julia Carabias); El Carricito Huichol de Pronatura; Calakmul de Unidos para la Conservación y Asociación Sierra Madre (Robles Gil, quien tiene estrecho vínculo con CI); El Edén, Yum Balám y la Alfredo V. Bonfil reciben apoyos privados.

\section{El caso peculiar de Conservation International (CI)}

La conocedora CI, que opera en más de 23 países ${ }^{10}$ y que tiene acuerdos por los que recibe más de 83 millones de dólares anuales - que destina a sus proyectos de conservación/biopiratería en el mundo para numerosas CMN como Monsanto, Intel, Pulsar, Hyseq, Bristol Squibb, Shaman y Dow Agrosciences, entre otras (CI, 1999)-, es quien casualmente ideó ${ }^{11}$ el concepto de corredor biológi$c o$, refiriéndose con ello a la integración de las distintas ANP en una gran faja que concentre las regiones prioritariamente megadiversas de los distintos biomas que integran el planeta, y que desde luego incluya activamente los asentamientos indígenas y campesinos que colindan o se encuentran dentro de estas ANP. Así, en un encadenamiento de ANP que se despliega a lo largo y ancho de varios estados nacionales (en su mayoría periféricos), cada corredor implica una homogeneización de las políticas, licencias y demás mecanismos

10 Belice, Bolivia, Botswana, Brasil, Colombia, Costa Rica, Ecuador, Estados Unidos, Fidji, Filipinas, Ghana, Guatemala, Guyana, Indonesia, Japón, Madagascar, México, Nueva Caledonia, Panamá, Papua Nueva Guinea, Perú, Islas Salomón y Surinam.

$11 \mathrm{El}$ término corredores fue usado por primera vez con un sentido estrictamente biológico por Simpson en 1936 en su estudio de dispersión entre continentes. Ya en 1949, Leopold indicaba que muchos animales, por razones desconocidas, no aparecen como poblaciones separadas; pero no fue sino hasta 1962, cuando Preston recomendaba por primera vez corredores biológicos entre reservas, que aparece el concepto de corredor biológico, más cercano al concebido actualmente. Recientemente, algunos estudios realizados en Estados Unidos, en gran parte llevados a cabo por CI y el Instituto Smithsoniano, aunque enfocados principalmente sobre el manejo del paisaje y no sobre problemas de mayor magnitud (por así decirlo), han sentado las bases tanto de un precedente legal como del supuesto entendimiento de un enfoque más integral, lo que ha sido modelo para el diseño de los corredores biológicos a nivel mundial de hoy en día. Esta nueva idea fue presentada públicamente por CI justo unos cuantos meses antes de la firma del Corredor Biológico Mesoamericano. 
para tener acceso y proteger la biodiversidad, e incluye a varios organizadores tales como CI (ligados a los ENC, las CMN y el Banco Mundial/GEF), que se encargan de enganchar los asentamientos indígenas para vincularlos al proyecto. De igual modo, reúne equipos de biólogos, etnobotánicos y demás especialistas para realizar un estudio pormenorizado de la riqueza biológica y su conocimiento, supuestamente para poder llevar a cabo el proyecto de conservación.

Son nueve los corredores biológicos que se están pensando a nivel planetario: ${ }^{12}$ en América, el Corredor de la Sierra de Nevada, el de América del Sur y el ya conformado Corredor Mesoamericano (véase Banco Mundial, 2000). En Europa, el del Mediterráneo. En África, el del Golfo de Guinea y el de Mozambique. En Asia, el de Indonesia y el del Océano Índico. Finalmente, distribuido a lo largo y ancho del Pacífico, el Corredor de las Filipinas, Polinesia y Micronesia.

Este proceso (conformación de corredores biológicos) ya comienza a concretarse a partir del diseño del estatuto legal del Corredor Mesoamericano ( $L a$ Jornada, octubre de 2000; Banco Mundial, 2000), puesto en marcha en octubre de 2000, el cual recibió del $\mathrm{GEF}^{13}$ - como parte del programa presupuestal ${ }^{14}$ otorgado a la región para el periodo 2000 al 2007 - la suma de 15.2 millones de dólares para su diseño y administración, que casualmente quedó en manos de CI. En otras palabras, se han iniciando los primeros pasos legales para construir un sistema de corredores bióticos a escala mundial, que sea funcional al sistema de bioprospección internacional, como necesidad del nuevo patrón tecnológico que comienza a perfilarse, y que al mismo tiempo, al delimitar las áreas de conservación, permita dar salida a la devastación ecológica que ha generado el capital a lo a largo de su historia.

12 Esencialmente, los nueve corredores biológicos son presentados por CI en sus publicaciones: Hotspots del año 2000 y Megadiversity de 1998 (ambos escritos por Myers y MittermeierGoettsch). Aunque sólo muestra las áreas en peligro, hay que agregar las zonas megadiversas colindantes y que aún no son clasificadas por CI como críticas.

13 El Fondo para el Medio Ambiente Mundial (GEF) fue constituido en 1992, cuenta con las aportaciones de 166 países y es el mecanismo financiero de la Convención de Diversidad Biológica, del Cambio Climático y del Protocolo de Cartagena sobre Bioseguridad. Es decir, es un mecanismo financiero que casualmente protege de manera selectiva la diversidad biológica mundial y que a la vez legaliza o restringe los avances biotecnológicos provenientes de la misma.

$14 \mathrm{El}$ programa incluye 31.10 millones de dólares para el fortalecimiento institucional de las áreas protegidas, 15.65 para las áreas protegidas de Los Tuxtlas, La Chinantla y La Montaña de Guerrero (PAIR), 6.733 millones de dólares para la Sierra Gorda y 7.5 millones para otras tres zonas más. Lo más alarmante del programa es que paralelamente se financian proyectos de bioprospección y apropiación de la diversidad genética (Antonio Castillo, 2000.) 


\section{HACIA UN SISTEMA MUNDIAL DE PATENTES: EL CASO DE LAS BIOPATENTES}

En la carrera para promover mecanismos exclusivos para recompensar a los inventores de nuevos productos y procesos biológicos, los estados nacionales, los organismos políticos y las grandes CMN, se ven forzosamente involucrados en la construcción de un sistema mundial de propiedad intelectual, debido a que para los capitales, el objeto técnico en cuestión (la biodiversidad y la biotecnología) afecta la gestión general de toda la biosfera y de ahí a todos los procesos mundiales de producción primaria y crecientemente de la secundaria.

En este sentido, Estados Unidos y otros países industrializados han presionado agresivamente en los años recientes para armonizar internacionalmente las leyes de propiedad intelectual, a modo de homogeneizar los distintos lineamientos, regulaciones y procedimientos, y sobre todo para hacer valer las patentes en todo el mundo. De esta manera, ya no sería necesario presentar las solicitudes de patentes en cada una de las oficinas de los diferentes países: una sola solicitud ante la Oficina de Patentes de Estados Unidos o en la de la Unión Europea, sería valida simultáneamente en varios países, y sobre todo en los ENP. La meta entonces, es incorporar a todos los países del orbe en un sistema único de patentes.

Lo anterior responde a que históricamente las leyes de propiedad intelectual se basan en el principio de soberanía nacional, por lo que cada país determina sus propios métodos para reconocerla y/o protegerla. Esto limita el robo de la biodiversidad y su conocimiento, y también obstaculiza el control de nuevas tecnologías por parte de los capitales involucrados en su desarrollo.

Todo lo anterior apunta hacia un proceso de perfeccionamiento y complejización de la propiedad privada en el mundo bajo su modalidad de propiedad intelectual, la cual se intenta formalizar en un sistema mundial.

A pesar de los requerimientos básicos para patentar, existe en las leyes de esta materia una doctrina bien establecida por la cual los productos de la naturaleza no son patentables. No obstante, antes de 1980, la mayoría de los ENP, así como muchos ENC, habían optado por no reconocer patentes sobre alimentos, medicinas u otros productos considerados como necesidades humanas básicas. Después de esa década, el sistema judicial de Estados Unidos dio un giro a esta doctrina, por medio de su nueva versión del requisito que interpreta que los productos de la naturaleza sin modificación del hombre no pueden ser patentados. Promovió así las biopatentes, dando la propiedad exclusiva de genes, plantas, animales y material genético humano a las CMN y actores propios de los estados nacionales (universidades, institutos, etc.), que por primera vez los aíslen, purifiquen, modifiquen y manipulen. 
Durante la Ronda de Uruguay del Acuerdo General sobre Aranceles y Comercio - GATT (1986-1994), hoy Organización Mundial del Comercio (OMC)—, los derechos de propiedad intelectual (TRIP) se convirtieron en objeto de negociación en el contexto del comercio internacional. Fue Estados Unidos quien peleó su inclusión en la agenda, bajo presiones de la industria farmacéutica y semillera, cuyos representante ${ }^{15}$ redactaron el texto que sirvió para su discusión y negociación. Finalmente, Estados Unidos ganó el forcejeo y el acuerdo sobre TRIP se convirtió en 1995 en el tercer pilar del régimen mundial del comercio - exceptuando el artículo 27.3(b), el cual aún está pendiente- ${ }^{16}$ junto a bienes y servicios. Como resultado, los integrantes del Comité sobre TRIP, cuyos miembros se leen como el quién es quién de las 500 empresas más grandes del mundo de Fortune, ${ }^{17}$ obligan a los países signatarios del GATT a adoptar legislaciones mínimas de propiedad intelectual, respecto a plantas y microorganismos, dentro de los siguientes cinco a 15 años.

Paralelamente, la Organización Mundial para la Propiedad Intelectual (WIPO) tiene como objetivo promover la cooperación entre países en el trámite de patentes, y establece convenios y tratados que intentan solventar las diferencias entre los regímenes jurídicos de cada país. Esto parte de la condicionalidad de los ENC hacia la periferia por medio de las negociaciones de la deuda y su servicio, cuyo pago puede ser directa o indirectamente en especie, ahora también en biodiversidad y su conocimiento, incluyendo, de ser posible, sus respectivos derechos de patente, proceso que se logra a partir de una desregulación de las inversiones en la periferia - Acuerdos Multilaterales de Inver-

15 En 1986, el presidente de Estados Unidos, Ronald Reagan, colocó junto a los representantes de la industria farmacéutica de ese país a Daniel Amstutz, un ejecutivo de primer orden de la semillera Cargill, como una de las figuras centrales en las negociaciones (Dawkins, 1997).

16 Este artículo señala que "Los miembros podrán excluir así mismo de la patentabilidad las plantas y animales excepto los microorganismos y los procedimientos esencialmente biológicos, que no sean procedimientos no biológicos o microbiológicos. Sin embargo, los miembros otorgarán protección a todas las variedades vegetales mediante patentes, mediante un sistema eficaz sui generis o mediante una combinación de aquéllas y éste. Las disposiciones del presente apartado serán objeto de examen cuatro años después de la entrada en vigor del Acuerdo sobre la OMC". Lo que hace confuso al artículo es que en ningún momento señala los parámetros de definición del sistema eficaz sui generis. También permite el patentamiento de los genes y procesos microbiológicos, además de otorgar un sesgo implícito a favor de los fitomejoradores y biotecnólogos; ya que carece de mecanismos para asegurar el "reparto equitativo de las ganancias, ello más bien se percibe más como un factor de exacerbación del robo de la naturaleza del planeta (Silvia Rodríguez y Grain, 2000.)

17 Los miembros que sobresalen en la Ronda de Uruguay son Bristol Myers, DuPont, General Electric, General Motors, Hewlett Packard, IBM, Johnson and Johnson, Merck, Monsanto, Pfizer, Rockwell y Time-Warner. 
siones (AMI) - para que los capitales puedan invertir libremente en sectores estratégicos como lo son institutos de investigación, JB, BsG, etcétera.

Con este sistema complejo de propiedad intelectual, lo que se perfila es la ampliación del control de las CMN sobre el mercado mundial. Su contraparte implica que la periferia no espere con ello ninguna seguridad, mayores inversiones, transferencia de tecnología de punta, ni mucho menos un mayor crecimiento económico. Más bien, la contribución de la periferia al subsidio de la investigación y desarrollo (I\&D) de los ENC aumentará, en un esquema de derechos de propiedad intelectual más sofisticado, que consolidaría el abismo tecnológico existente entre ambos, en términos de un escaso acceso a la tecnología de vanguardia, así como en la disposición de información científica por parte de los ENP.

Aún más complejas resultan las acciones directas que aplican los ENC para penetrar las estructuras nacionales periféricas, de manera que puedan acceder y apropiarse de sus recursos. Destacan, entre otros, los casos de: 1) las modificaciones al Artículo 27 constitucional en México impulsadas por el Banco Mundial, referentes a la propiedad de la tierra, las cuales redefinen el acceso a sus recursos; 2) las nuevas regulaciones para el acceso a los recursos genéticos en Costa Rica, expresadas en su Ley de Biodiversidad, la cual es impulsada por InBio; y 3) el caso del decreto MP 2052 en Brasil, impulsado por Novartis y Bioamazonia, que deja en manos de un Consejo Ministerial el acceso y uso de sus recursos.

Por todo lo anterior, es evidente que el proceso de globalización de un sistema mundial homogéneo de patentes se está convirtiendo en la punta de lanza de las grandes CMN para monopolizar el desarrollo del patrón tecnológico en construcción, a lo que se suma además el creciente y complejo proceso de biopiratería a nivel planetario, solapado e incluso impulsado por los distintos ENP, y que adquiere fuerza a partir de los intereses geopolíticos y geoeconómicos que mueve. Es de esperarse que ambos fenómenos, que se intensificaron en los últimos años del siglo xx, lo hagan aún más en los primeros años del siglo XXI. No es casual que, según datos de Mooney, el ritmo de aumento de biopatentes sea cada vez mayor, y que $90 \%$ sea controlado por las grandes CMN. En 1980 el número de patentes por año era de 10 mil, y para 1999 era ya de 176 mil. De los seis millones de patentes que existen, cerca de tres millones ${ }^{18}$ corresponden sólo a materiales biológicos. Tan sólo en 1990, el total

18 Datos que según RAFI son subestimados, puesto que generalmente las patentes son secretas hasta que son aprobadas. Los tres millones tan sólo corresponden a tres empresas: Celera, Human Genomic Science e Incide Corporation (RAFI, 1999). 
de ganancias generadas por el cobro de licencias de patentes fue de $15 \mathrm{mil} \mathrm{mi-}$ llones de dólares, para 1998 se había alcanzado la cifra de 100 mil millones y se calcula que para el 2005 aumente a medio billón de dólares por año (Mooney, 1999: 82).

\section{El NIH y compañía, una criatura de excelencia en la era biotecnológica}

Como resultado del término oficial de la investigación en armas ofensivas biológicas y químicas (previo a 1972), cuando las instalaciones de Fort Detrick fueron el cuartel central de las unidades de los militares dedicadas a dicho fin, Estados Unidos desocupó parcialmente (a partir de 1972) la instalación de Fort Detrick, y el Instituto Nacional de Salud (NIH) se mudó allá. Fort Detrick es compartido ahora por el National Cancer Institute (NCI), National Institute for Discovery Science (Ninds), varios grupos médicos del ejército de Estados Unidos y una agencia médica de la Agencia de Inteligencia en Defensa (DIA). Las unidades del ejército en Fort Detrick incluyen al Instituto de Investigación Médica en Enfermedades Infecciosas (AMRIID) y un grupo que investiga contramedidas a agentes bélicos biológicos; también alberga la colección de materiales biológicamente dañinos del ejército de Estados Unidos en una de las instalaciones más seguras del mundo. ${ }^{19}$ Detrás de las numerosas medidas de bioseguridad existe una biblioteca de muestras de virus extremadamente virulentos, tales como el ébola (objeto de investigaciones en marcha por científicos del Departamento de la Defensa de Estados Unidos como parte de la elaboración de armas bioquímicas y bacteriológicas).

19 El United States Army Medical Research Institute of Infections Diseases (USAMRID) comprende alrededor de 25 laboratorios, seis de ellos clasificados como de máxima seguridad - grado BL4 (Biosecurity Level 4) -; de estos últimos no existen más de una docena en el mundo. La clasificación de Biosecurity Level (BL) se refiere principalmente en el caso de BL1 al manejo de muestras biológicas para prácticas de laboratorio en universidades, el BL2 alude al uso de muestras biológicas con cierto grado de manipulación que requieren cuidado - caso de los laboratorios comerciales y algunas investigaciones de formación universitaria-, el BL3 implica el manejo de materiales biológicos semiinfecciosos, generalmente para investigaciones de institutos privados y algunos públicos que están vinculados a grandes universidades como serían algunos institutos de patología de distintas universidades en el mundo. El BL4 hace uso y manipula muestras biológicas altamente agresivas, infecciosas e inestables. Generalmente son investigaciones llevadas a cabo por instituciones militares y específicamente para la producción de armas y en algunos casos con fines médicos. Se trata de materiales como toxinas (Ricin, Saxitoxin, Staphylococcus enterotoxin B y otras), cepas virales (Venezuelan equine encephalitis - encefalitis - , VIH — sida - ébola, etc.) y bactereológicas (Bacillus anthracis - anthrax -, Yersinia pestis - plaga bubónica -, entre otras). Véase Graham S. Pearson, 1998. 
Las oficinas y las colecciones biológicas del Ninds, así como numerosos investigadores del NCI, están en Fort Detrick, el cual aloja además las colecciones del Programa de Desarrollo Terapéutico del NCI, que es líder en la recolección y análisis farmacológico de plantas y otros especímenes biológicos de todo el mundo. Lo más llamativo, es que tanto el NIH como la Armada en Fort Detrick hacen contratos gubernamentales con empresas privadas, filtrándose en su administración para asegurar y controlar el tipo de investigación que realizan. Por ejemplo, la compañía Science Applications International Corporation (SAIC), en San Diego, es una firma sostenida privadamente y que se especializa en trabajos de alta tecnología para el Departamento de Defensa de Estados Unidos y agencias de inteligencia extranjeras. El directorio de SAIC incluye, o ha incluido recientemente, a los secretarios de defensa actuales y anteriores, y a los directores de la Agencia Central de Inteligencia (CIA), entre otras personas ligadas íntimamente a las operaciones de inteligencia militar de Estados Unidos y de otros países (RAFI, 1996a).

La primera solicitud de patente (publicación número WO93/03759), presentada a nombre del U.S. Department of Health and Human Services (Departamento de Salud de Estados Unidos) y el NIH, pretendió reclamar los derechos sobre una línea de células T de un habitante de Papúa, Nueva Guinea. De acuerdo con la solicitud de patente, en mayo de 1989 fueron tomadas muestras de sangre de 24 personas pertenecientes a la comunidad Hagahai, de la provincia de Madang, Nueva Guinea. Esta línea de células, la primera de su clase de un individuo de Papúa (también en Nueva Guinea), es potencialmente útil en el tratamiento y el diagnóstico de personas infectadas con una variante del virus HLTV-I.24. El virus humano T-linfotrópico tipo I (HTLV-I) está asociado con leucemia en adultos y con una enfermedad neurológica crónica degenerativa. La nueva línea de células posee un valor potencial para poder entender el mecanismo que regula el aumento o la supresión de la respuesta inmunológica del organismo ante este virus (Patente Estados Unidos, núm. 5397 696). Véase RAFI, 1999a.

El segundo reclamo de patente (WØ-9215325-A) fue presentado a nombre del Departamento de Comercio de Estados Unidos sobre la línea de células T humanas de una mujer de 40 años de edad de Marovo Lagoon, en Western Province (Provincia Occidental), y de un hombre de 58 años de edad de la provincia de Guadalcanal. Ambos sujetos son habitantes de las Islas Salomón. Las muestras de sangre fueron obtenidas en marzo y agosto de 1990. Esta línea de células podría ser útil para producir vacunas y/o servir para el diagnóstico del virus humano T-linfotrófico tipo I (RAFI, 1999a). 
Para mayo de 1993, RAFI describió el Proyecto de Diversidad del Genoma Humano, cuyo objetivo es recolectar e inmortalizar tejidos humanos de 722 poblaciones humanas, incluyendo varias comunidades nativas alrededor del mundo. Para confirmar sus más graves temores, en agosto del mismo año, mientras investigaba datos del American Type Culture Collection (ATCC), RAFI descubrió que el gobierno de Estados Unidos estaba reclamando derechos de patente dentro de seis países y a nivel mundial sobre la línea de células de una mujer panameña, india guaymi, de 26 años de edad (WO 9208784). Véase RAFI, 1999a.

El NIH no sólo tiene muestras de tejido humano de Colombia, sino que cuenta con enormes cantidades, que incluyen muestras de sangre de al menos 27 grupos de "indios colombianos de buena salud y de [...] tribus culturalmente distintas distribuidas en 12 departamentos (o estados), ocupando territorios marcadamente diferentes" (RAFI, 1999a). Además de las muestras de sangre en el NIH y el CDC, RAFI ha confirmado que una variedad de investigadores en Estados Unidos y Japón han estado usando tejido humano colombiano: la Universidad de Harvard (Estados Unidos) tiene al menos tres líneas celulares de Tumaco [American Journal, vol. 52(2)], la Universidad de Kyoto (Japón) tiene un número no revelado de muestras de habitantes nativos de Colombia [National Academic Science, vol. 91(3)], la Universidad de Cornell (Estados Unidos) informa que está elaborando la secuencia de parte de la cepa de HTLV encontrada en muestras de sangre del pueblo wayuu en Colombia [Japanesse Journal, vol. 84(12)], la Universidad de Kyushu (Japón) tiene líneas celulares de áreas de Colombia donde la infección con HTLV es endémica [Neurology, vol. 42(11)], y la Universidad de John Hopkins (Estados Unidos) tiene 1077 muestras de sangre proveniente de Tumaco [Japanesse Neurology, vol. 87 (1)].

Otros ejemplos de tráfico de muestras son: la Universidad de Yale (Estados Unidos), que tiene 703 muestras del pueblo kayapo de Brasil, con las cuales se están llevando a cabo investigaciones relacionadas con el HTLV. El Instituto Nacional del Cáncer (NCI) dice que tiene muestras de sangre provenientes de "adultos de 13 tribus indias asiladas de América Central y América del Sur", y específicamente provenientes de los pueblos de Kayapo y Kraho de Brasil. El NCI también declara que está trabajando con muestras de tejido humano provenientes de China, las Indias Occidentales Francesas, Haití, Mauritania, Guinea-Bissau, Costa de Marfil, República Central de África, Zaire, Guyana Francesa, Perú, Islas Salomón y Papúa Nueva Guinea. Qué parte de éstas provienen de pueblos indígenas no está claro. Además, el CDC confirma 
que ha usado muestras de sangre provenientes de Brasil, Etiopía, Indonesia, Jamaica, Japón, México, Panamá, Perú y Somalia en investigación sobre el HTLV, caso en el que tampoco se tiene clara la porción de muestras que provienen de pueblos indígenas. Asimismo, la Universidad de Kyoto, además del trabajo mencionado anteriormente, está usando muestras de sangre provenientes del pueblo Ainu (Japón), Gabón, Ghana e India. También la Universidad de Kyushu (Japón) tiene muestras de tejido humano provenientes de Jamaica y Chile (RAFI, 1996a). Todas estas muestras que se trafican entre los $\mathrm{NIH}$, organizaciones y universidades, son posibles de patentar si es que contienen genéticamente un valor comercial para la industria farmacéutica mundial.

Más complejo se vuelve el asunto de los NIH cuando parecen tener las colecciones más grandes de tejidos de pueblos indígenas, y es el único grupo que hasta ahora las patenta. En este contexto cabe señalar que, evidentemente, muchas de las investigaciones del Ninds y el NCI, ambos parte del NIH, sobre tejidos humanos no tienen lugar en las instalaciones centrales del NIH en Bethesda, cerca de Washington, D.C., sino más bien en las instalaciones de Fort Detrick, Maryland, justo donde se encuentra todo este complejo de investigaciones.

\section{BIOPIRATERÍA EN MÉXICO}

Ante la magnitud de la biopiratería en el mundo, el caso de mi país resulta central, dada la considerable magnitud de su diversidad biológica y cultural, por lo que dedicaré este apartado para presentar el tema.

Es importante, entonces, destacar la riqueza biológica y cultural del país, ya que alberga entre el 8 y el $12 \%$ del total de las especies del planeta (Casifop/RAFI, 2000), se coloca entre el cuarto y quinto lugar (Mittermeier) ${ }^{20}$ de diversidad biológica y concentra una gran diversidad cultural distribuida a lo largo y ancho del territorio nacional (sexto lugar del mundo), ${ }^{21}$ desde las vastas zonas áridas del noroeste hasta los bosques tropicales húmedos del sureste. Lo anterior, en parte, se debe a la peculiar posición geográfica del país, donde

20 Según Mittermeier, México se ubica en el quinto puesto en diversidad biológica, precedido por Brasil, Indonesia, Colombia y Australia. Le siguen Madagascar, Perú, China, Filipinas, India, Ecuador y Venezuela (Mittermeier, 1998).

21 Los países con mayor diversidad cultural (con base en el conteo de lenguajes endémicos), según Harmon, en orden descendente son: Papúa Nueva Guinea, Indonesia, Nigeria, India, Australia, México, Camerún, Brasil, Zaire, Filipinas, Estados Unidos, Vanuatu, Tanzania, Sudán, Malasia, Etiopía, China, Perú, Chad, Rusia, Islas Salomón, Nepal, Colombia, Costa de Marfil (Harmon, D., 1996). 
se intersectan diferentes regiones biogeográficas continentales y mundiales: la región biótica neártica y neotropical (Mittermeier y Goettsch, 1992: 67).

BIODIVERSIDAD DE MÉXICO

\begin{tabular}{lccc}
\hline Especies & $\begin{array}{c}\text { Número } \\
\text { de especies }\end{array}$ & Total mundial & $\begin{array}{c}\text { Lugar de México } \\
\text { en el mundo }\end{array}$ \\
\hline Mamíferos & $449 \mathrm{a})$ & 4170 & $2^{\circ}$ \\
Aves & 1150 & 9198 & $20^{\circ}$ \\
Anfibios & $282 \mathrm{~b})$ & 4184 & $4^{\circ}$ \\
Reptiles & $717 \mathrm{c})$ & 6300 & $4^{\circ}$ \\
Mariposas & $2052 \mathrm{~d})$ & & \\
Plantas vasculares & $25000 \mathrm{e})$ & 250000 & \\
Algas macroscópicas & 1500 & & \\
Briófidas & 2000 & & \\
Pteridiófitas & 1500 & & \\
Total & 29650 & & \\
\hline
\end{tabular}

a) El primer lugar en el mundo lo ocupa Indonesia con 515 especies.

b) $63 \%$ son endémicas en nuestro país.

c) $80 \%$ son endémicas en México (574 especies).

d) 52 especies pertenecientes a la familia papilionidae y 2000 diurnas.

e) Se calcula que a esta cifra se podrían incorporar de 25000 a 30000 que faltan por estudiar.

FUENTE: Lara y Bravo et al., "Informe del estado del desarrollo económico y social de los pueblos indígenas de México", en Lara, Bravo y Rodríguez, Pueblos indios, biodiversidad y política ambiental, México, Programa Universitario del Medio Ambiente-UNAM/INI, abril de 1990.

Asimismo, México es uno de los principales centros de domesticación de plantas cultivadas del planeta (una de las regiones del planeta también conocidas como centros Vavilov). Cerca del $25 \%$ del total de especies de plantas superiores que hay en el país tiene algún uso. Sobresalen el maíz, ${ }^{22}$ frijol, chile, aguacate, jitomate, amaranto, calabaza, cacao, tabaco y la vainilla (Ramamoorthy, Bye, 1998). También es el caso del sahuhui, la chía, el haba, el guaje, el camote, la yuca, jícama, el girasol; numerosas frutas (piña, chirimoya, anona, papaya, zapote negro y blanco, etcétera), estimulantes como el maguey pulquero, el peyote y el toloache; fibras vegetales (distintas variedades de henequén e izote), entre otras variedades (Casifop/RAFI, 2000:3). En general, de acuerdo con la Comisión Nacional para el Estudio y Uso de la Biodiversidad de México (Conabio), la diversidad de alimentos que se consumen en México se sustenta en más de un centenar de plantas cultivadas, 600 espe-

22 "México alberga 41 complejos raciales de maíz y miles de variedades. El banco de germoplasma sostenido por el Centro Internacional de Mejoramiento del Maíz y del Trigo (CIMMYT) en México tiene 10965 muestras, de las cuales hay 3532 que corresponden a variedades mexicanas" (Alejandro Nadal, 2000. Citado en Casifop/RAFI:4). 
cies de plantas silvestres, 300 de peces, moluscos y crustáceos y más de 100 de insectos.

Es por todo lo anterior, que en la actualidad son las sociedades rurales, y en particular las indígenas, quienes han preservado y siguen preservando el germoplasma no sólo vegetal (que constituye la mayor parte de los alimentos básicos que se consumen en el país), sino la totalidad del que está presente en el medio que las rodea.

Así, de manera contrastante, encontramos que el territorio concentra una amplia variedad de recursos naturales: suelos, agua, flora y fauna. La coincidencia entre las regiones culturalmente más diversas y ricas en germoplasma vegetal y animal, al igual que en el resto del mundo, no es casual sino causal. Se ha calculado que las áreas habitadas por pueblos indígenas albergan entre 55 y 60 por ciento del total nacional, cifra que considera exclusivamente las especies de flora y fauna continentales (INI/Conabio, 1999). Ello explica la razón por la que estos grupos sociales son núcleos de un diversificado acervo de conocimientos y saberes asociados con los ciclos de la naturaleza y las propiedades de la flora y la fauna silvestre, aspectos inherentes a su concepción del mundo de carácter precapitalista.

NÚMERO DE ESPECIES VEGETALES UTILIZADAS Y NOMBRADAS ENTRE ALGUNOS PUEBLOS INDÍGENAS

\begin{tabular}{lcc}
\hline Grupo étnico & Especies presentes & $\begin{array}{c}\text { Especies nombradas } \\
\text { y utilizadas }\end{array}$ \\
\hline Tarahumara & 1000 & 398 \\
Seri & 2703 & 516 \\
Nahua & 8500 & 1597 \\
Purépecha & 500 & 230 \\
Maya & 1936 & 909 \\
Tzeltal & 10000 & 1040 \\
\hline
\end{tabular}

FUENTE: Informe del inI y la Conabio titulado Pueblos indios, biodiversidad y política ambiental, México, 1999.

Considerado lo anterior, y al ser vecino de Estados Unidos -el principal promotor de la biotecnología y biopiratería en el nivel mundial-, México se ha convertido en un país ejemplar para montar muchas de las variantes más sofisticadas y agresivas del robo de biodiversidad. En este panorama, destacan cuatro contratos de bioprospección que, como principalmente Casifop y RAFI lo han denunciado, conforman la punta del iceberg mexicano (Casifop/RAFI, 
2000). ${ }^{23}$ En su documento, La biopiratería en México: la punta del iceberg, se señalan los siguientes cuatro contratos aquí retomados y ampliados:

a) Sandoz (Novartis)/Unión de Comunidades Forestales Zapotecas y Chinantecas (Uzachi) de la Sierra de Juárez en Oaxaca.

b) ICBG/Zonas Áridas (Bioactive agents from dryland plants in Latin America), el Jardín Botánico y la Facultad de Química de la unAm/Universidad de Arizona, Luisiana y Perdue/American Home Products y American Cyanamid.

c) ICBG Maya (Colegio de la Frontera Sur) Universidad de Georgia/Molecular Natural Limited.

d) Instituto de Biotecnología de la UNAM/Diversa.

\section{Caso a}

Dado el grado de confidencialidad de los proyectos, lo poco que se sabe es que respecto al contrato de Sandoz (ahora Novartis), ERA y la Uzachi - Bio Lead Project-, es que éste forma parte de un programa internacional de investigación de Novartis, que se desarrolló también en Panamá y la India. A diferencia de los otros proyectos, en este caso no participaron universidades o centros de investigación mexicanos - pese a que fue propuesto inicialmente al Instituto Politécnico Nacional y la UNAM. El contrato se firmó directamente con una asociación civil consultora, ERA, y una asociación de comunidades indígenas, la Uzachi. Los términos del contrato incluyen el establecimiento de un labo-

23 Según este mismo documento, la labor de denuncia y protestas de pueblos indígenas y organizaciones de la sociedad civil ha servido para sacar a la luz la magnitud de este saqueo. En México, señala el documento, destacan el Centro de Análisis Social, Información y Formación Popular (Casifop); RAFI ahora ETC Group (Action Group on Erosion and Technology Concentration), $<$ www.biodiversidadla.org $>$ y <www.rafi.org $>$; el Ceccam (Centro de Estudios para el Cambio en el Campo Mexicano), <www.ceccam.org.mx>; la CIEPAC, <www.ciepac.org>; el Compitch (Consejo de Médicos, Parteras Indígenas Tradicionales de Chiapas), entre los más importantes. Igualmente, cabe señalar a intelectuales como Alejandro Nadal del Colmex, Silvia Ribeiro de RAFIMéxico, Armando Bartra, Ana de Ita, Andrés Barreda de Casifop, entre otros. Véase también de este último: Andrés Barreda, Atlas geoeconómico y geopolítico del estado de Chiapas, México, Tesis de Doctorado en Estudios Latinoamericanos de la FCPys-UnAM, 1999. En el nivel mundial cabe también bosquejar el quién es quién en la denuncia y lucha contra la biopiratería, proceso en el que gracias a la interrelación de los actores se han venido aclarando conceptos y problemáticas de lucha. En ese escenario RAFI se ha colocado en el centro desde fines de la década de los noventa del siglo xx. Igualmente se puede identificar a Grain, onG que se ha enfocado geográficamente en Europa, aunque también en coordinación con Redes-AT (Red de Ecología SocialAmigos de la Tierra, Uruguay), en América del Sur. Ambas ONG han venido trabajando por su parte y en conjunto para el caso de América Latina. Además, podemos identificar organizaciones campesinas e indígenas como la de Vía Campesina, el movimiento de los Sin Tierra, entre otras. Académicos y luchadores sociales, como Vandana Shiva (India), Joan Martínez Alier (España), etcétera. 
ratorio en Sierra Juárez, y la capacitación de personal para trabajar en él con el fin de enviar cada año dos mil muestras al laboratorio de Sandoz en Suiza. ${ }^{24}$ El laboratorio le costó 50 mil dólares a Sandoz, multinacional que también pagó 10 mil dólares anuales por las muestras (una vez recibidas), los salarios de los técnicos y los costos de administración y asesoría. El contrato también estipula que si se desarrolla algún fármaco a partir de muestras enviadas, se le pagaría un monto fijo y único a la Uzachi de entre uno a dos millones de dólares, dependiendo del valor comercial del mismo, ello sin haber ningún acuerdo de pago de regalías. ${ }^{25} \mathrm{Al}$ parecer, formalmente terminó en 1999 y extrajo miles de muestras de hongos micro y macroscópicos de la Sierra Norte de Oaxaca a lo largo de dos años (al menos 3 mil muestras por año). El objetivo central fue identificar componentes activos prioritariamente para posibles curas del sida y cáncer, entre otros usos, ${ }^{26}$ e incluye las especies de hongos comestibles de las localidades donde se desarrolló la investigación, así como de especies forestales no maderables. ${ }^{27}$ En total se calcula entre nueve y diez mil muestras de hongos micro y macroscópicos (Casifop/RAFI, 2000:11).

\section{Caso b}

En el caso de American Cyanamid, filial de American Home Products, están involucradas las universidades de Arizona, Luisiana (G.W. Hansen's Disease Center) y Perdue; asimismo, la Facultad de Química y el Jardín Botánico de la UNAM. Según los informes del proyecto, ${ }^{28}$ ese conjunto de contratos se formalizó en 1992, con la CBD impulsada por el Banco Mundial y patrocinada por el GEF. El proyecto incluye además de los copartícipes mexicanos, a los de Argentina y Chile: el Instituto Nacional de Tecnología Agrícola de Argentina, la Universidad de Patagonia (Argentina) y la Universidad Pontífice Católica de Chile.

24 Casifop/RAFI, op. cit., p. 11.

25 Ibid., p. 12.

26 "La investigación puede fácilmente ligarse a las necesidades económicas y sociales, como es el caso de la bioprospección en busca de nuevos fármacos y agroquímicos para uso humano, desarrollo de agentes de control biológico y el manejo sustentable de bosques, a través de la comprehensión y utilización de sus componentes de hongos." (Casifop/RAFI, op. cit., p. 17.)

27 "Según el supervisor científico y co-firmante del proyecto, Ignacio Chapela, investigador de la Universidad de Berkeley, los hongos son organismos biológicos estratégicos pero desconocidos, mediadores de diversos procesos de equilibrio en la biosfera y la tecnosfera: en las áreas de conservación del medio ambiente, la salud, los procesos agroforestales y la producción agroindustrial de alimentos. De ahí que [...]este proyecto[...] pueda ser considerado como un programa ubicado en la frontera del conocimiento." (Ibid., p. 17).

28 Departamento de Agricultura de la Universidad de Arizona:

<http://ag.arizona.edu/OALS/ICBG/reports/1998winter.html> 
El proyecto para la fracción de México, al mando del doctor Robert Bye - parte del cuerpo administrativo y docente de la UNAM-, está recolectando muestras de cactus, xerófitas y otras plantas de los desiertos de los estados de Sonora, Sinaloa, Chihuahua, Durango, San Luis Potosí, Puebla, Nuevo León, Oaxaca y Chiapas. Obtuvo de 1993 a 1997 alrededor de 3500 extractos, y el contrato se renovó hasta el 2003.

Lo más riesgoso de este acuerdo en el caso de México es el libre acceso a los Bancos de Información Genética del Jardín Botánico de la UNAM. Según el propio ICBG, el doctor Bye "[...]está desarrollando las bases de datos más grandes de todo el proyecto de las zonas áridas, sobrepasando las expectativas que se tenían para los tres países en su conjunto". ${ }^{29}$ Esto se debe a que hoy en día las CMN farmacéuticas y químicas pueden construir compuestos activos a partir de la búsqueda de estructuras moleculares ad hoc a un uso específico. Como resultado, las bibliotecas de químicos originales (novel chemical libraries) se han convertido en un negocio importante en el que la mayoría de las CMN involucradas, como Diversa y CombiChem, por mencionar algunas, son estadounidenses.

No sorprendería que Bye tenga además acceso a la base de datos del Herbario Nacional, administrado también por la UNAM, y mucho menos que la incluyera en el sistema de información que está preparando para el ICBG. Lo anterior es grave, ya que según datos de Patricia Dávila (jefa del Departamento del Instituto de Biología de la UNAM), en México cerca del 55 al 60\% de las especies de los herbarios mexicanos son endémicas, colocándose en los primeros lugares de entre los demás jardines de la periferia.

\section{Caso c}

El proyecto entre el ICBG Maya, el Colegio de la Frontera Sur (Ecosur), la Universidad de Georgia y la empresa inglesa Molecular Natural Limited, firmado en 1998, de igual modo, busca sustancias activas (especialmente para la industria farmacéutica), pero se centra en el estado de Chiapas. Lo crítico radica en que bajo el mando del doctor Brent Berlin, de la Universidad de Georgia, se está haciendo uso del conocimiento y la mano de obra de las comunidades locales. A pesar de que el proyecto se firmó en 1998-1999, las investigaciones etnobotánicas de Berlin en la región comenzaron desde 1987, cuando ini-

29 Textual: "Dr. Robert Bye's department has expanded its horizons to the point where their ideas and their capability to realize those ideas are cutting edge. They strive to achieve what other have not yet achieved. This is technology transfer!" (ibidem). 
ció un estudio de la medicina etnobotánica maya (Berlin y Berlin, 1996; Berlin, 2000). Brent publicó en 1996 un libro que describe pormenorizadamente el uso médico de la biodiversidad de Chiapas, su localización y abundancia. Dicha publicación la llevó a cabo junto con Elois Berlin, y un equipo grande de botánicos, farmacólogos, antropólogos y etnobotánicos de la Universidad de Georgia, el Ecosur, la Academia de Ciencias de California (Berkeley), la Universidad de Idaho, el Instituto Smithsoniano y el Instituto Mexicano del Seguro Social.

El proyecto de bioprospección está buscando validar el patentamiento de las investigaciones añejas de Berlin, mediante la reciente solicitud de comercializar los componentes activos que supuestamente apenas van a extraer. Sin embargo, también se trata de reconfirmar el trabajo de Berlin pero ahora en el nivel molecular. Hasta 1999 había recolectado casi seis mil muestras tan sólo en comunidades como Chenalhó, Oxchuc, Tenejapa y Las Margaritas. Se instalaron JB por regiones. El total de jardines del proyecto es cerca de 15 y 16 , de los cuales cuatro están completos y del resto aún están recabando muestras.

\section{Caso d}

Este contrato, vigente desde 1998, fue realizado entre la UNAM, mediante el Instituto de Biotecnología, y la empresa Diversa. Jorge Soberón M., actual secretario ejecutivo de la Conabio (Comisión Nacional para el Conocimiento y uso de la Biodiversidad), aprobó dicho proyecto de bioprospección comercial a cambio de que el Instituto de Biotecnología recibiera el equipo necesario para que maquilara muestras biológicas. Diversa pretende encontrar organismos que viven en condiciones extremas, de los que se puedan obtener sustancias activas de gran potencial económico. Se le conoce como la empresa que logró el primer acuerdo de bioprospección en Estados Unidos en 1997 (Yellowstone National Park), ha reclamado 700 patentes de enzimas y tiene acuerdos con Hoffmann-La Roche, Dow Chemical Co., Sigma, entre otras. $\mathrm{El}$ acuerdo le permite a Diversa tener acceso a las ANP de México, incluyendo las llamadas reservas de la biósfera de propiedad y uso exclusivo de la Federación, además de que se da por aceptado el derecho a patentar en otros países la biodiversidad mexicana, dado que no existe en nuestro país legislación alguna al respecto. Lo más grave radica en los contratos o acuerdos paralelos que tiene Diversa. Tal es el caso del que tiene con Celera, empresa responsable del desciframiento del genoma humano. Basta con revisar su página de internet para confirmar que han acordado descifrar distintos genomas y patentar los genes únicos que se llegaran a encontrar en la biblioteca genética 
de Diversa. Coordinado a tal acuerdo, hay otro que llama la atención: el celebrado entre Celera y los Laboratorios Sandía. Este último es una institución esencialmente militar encargada de algunas de las investigaciones de alta confidencialidad del Pentágono (Delgado, 2001). Por lo que podríamos afirmar que la UNAM está maquilando, en términos de ingeniería genética (biomaquila), ${ }^{30}$ muestras biológicas mexicanas con potencial comercial a 50 dólares cada una, según el contrato firmado. Así, se ceden todos los derechos de patente a Diversa, la que a su vez los puede transferir a otros, incluyendo el Departamento de Defensa de Estados Unidos.

Aunque estos cuatro contratos destacan por ser los de mayor envergadura, no son las únicas actividades de biopiratería en el país. Son tan sólo la punta del iceberg mexicano, porque hay otros casos como el de Savia/Pulsar que lleva varios años en Montes Azules (Chiapas) operando con el apoyo de la Secretaría del Medio Ambiente, cI y algunos biólogos, ecólogos y biotecnólogos de la UNAM - probablemente en colaboración con Brent Berlin. Igualmente, se sabe que han estado presentes en los estados de Oaxaca y Chiapas, etnobotánicos y biólogos de Japón y de Alemania, sin embargo, no hay documentación que avale las denuncias indígenas al respecto.

\section{Algunas precisiones respecto a la biopiratería en el mundo y alternativas de contratendencia}

Desde hace varios años, múltiples empresas y CMN involucradas en biopiratería, así como en el desarrollo de las tecnologías que hacen uso de la biodiversidad, han descalificado las denuncias y críticas aludiendo que muchos acuerdos de bioprospección son de carácter estrictamente científico, y en el caso de ser de carácter comercial, argumentan que la moderna forma de extraer y usar la biodiversidad comienza a ser pagada y por lo tanto se vuelve generadora de recursos para los ENP, mediante reparto de beneficios en forma dineraria, equipo técnico, calificación científica, programas de desarrollo social/ambiental, entre otros.

Lo que nunca se dice es que, en caso de ser de carácter científico, generalmente están involucrados no sólo institutos de investigación, sino también empresas y CMN, lo que deja a su arbitrio el uso exclusivamente científico o no de las muestras y conocimiento obtenidos. En el caso de ser comercial, hasta hoy en día, según RAFI, no se ha registrado en el mundo un solo pago por regalías, aunque sí se haya acordado y otorgado el soporte técnico necesario para extraer la riqueza biológica planetaria.

30 Término ideado por Andrés Barreda (Barreda, 1999). 
Lo anterior responde a un proceso complejo: por un lado, resulta indispensable otorgar los medios técnicos para extraer la biodiversidad, convirtiendo a los propios ENP, justamente los que son saqueados, en biomaquiladores al servicio de los ENC. Por otro lado, y dado el intenso proceso de fusiones entre las CMN y las empresas vinculadas al desarrollo biotecnológico, resulta difícil seguir el camino de los recursos biológicos extraídos, ruta que es aún más enmarañada, dada la dificultad para determinar qué productos están siendo usados, debido al intrincado proceso bioindustrial.

Como respuesta al complejo escenario descrito a lo largo del presente artículo, la resistencia aislada frente a estos capitales, sobre todo cuando se trata de comunidades indígenas, es una batalla difícil, si no es que perdida. Considérese el caso clásico entre Costa Rica y Merck, donde esa CMN, además de haber adquirido el apoyo del Estado, su capital sobrepasa el PIB de dicho país y tiene más abogados de los que ahí se forman. Entonces, ¿cómo pueden las aisladas comunidades agrícolas e indígenas costarricenses dar una pelea efectiva?

La alternativa está, primero, en la construcción de un tejido social fuerte y organizado que se conecte con lo local (ciudad/campo) y lo nacional, y qué mejor si se liga a lo internacional. Necesariamente, como segundo punto, la construcción social de una alternativa debe a la vez vincular e incidir en el Estado, como se muestra en la experiencia histórica mexicana del proceso de la nacionalización de las empresas petroleras, para dar cuenta del peso que puede y debe adquirir la dinámica social sobre la estructura gubernamental. Por ello se requiere cautela para no caer en el error de tomar como positiva la propuesta de otorgar a los indígenas derechos sobre el uso y manejo de sus recursos, lo que se ha hecho en distintos ENP. Para que fuese socialmente positiva, tendría y tiene que ser entendida, asumida y respetada por los distintos actores sociales como derechos colectivos y no individuales. Algo que no se ha logrado en México por los vacíos presentes en la aprobada Ley de Derechos Indígenas en abril de 2001. Esa ley deja a las comunidades defensivamente débiles y aisladas frente al mercado, que de antemano presupone la cancelación de la colectividad, permite a las CMN insertar a las comunidades en esa lógica mercantil por medio de contratos individuales, basados en su concepción particular de lo que son los derechos colectivos e individuales, y entonces privados, de manera que tales CMN se colocan en una posición ventajosa. Por lo anterior, habría que desmontar la idea de la supuesta neutralidad del mercado, para poder medir la correlación real de fuerzas entre capitalistas y la resistencia. 
En este tenor, no hay que perder de vista el papel central de las luchas indígenas y campesinas en distintas partes del mundo, como impulsoras iniciales de una concientización social. Tampoco hay que desestimar que su lucha tiene un límite en el que es necesario que nos incluyamos los distintos miembros del sujeto social proletario. ${ }^{31}$

El subcomandante zapatista Marcos lo plantea así:

... nosotros nos quedamos sin salidas, la única forma de hacernos fuertes era salir, era caminar, pero no teníamos ningún pie, teníamos la voz y la mirada, pero teníamos que llevar esa voz y esa mirada adonde fuera escuchada y adonde esa mirada tuviera dirección, entonces tuvimos que pedir prestados los pies de otros. A la hora que tuvimos que pedir prestados esos pies de otros tuvimos que construirlos porque no existían, entonces empezamos a hablar, a hablarle al otro, empezamos a darle un rostro, el que otros le negaron. Empezamos a llamarlos y pidiéndoles que fueran los pies[...] ese muñeco se encuentra con el problema de que los pies dicen que quien manda es la cabeza, la historia está hecha así, lo que no ocurre es que los pies manden a la cabeza, pero la cabeza necia con que los que tienen que mandar son los pies. Finalmente, la cabeza dice lo que todos están pensando y nadie se atreve a decir, que en el recorrido se dan cuenta que el mundo está de cabeza, que tiene el que no necesita y el que necesita no tiene nada. Finalmente ese día, mañana, llegan al lugar donde éste se puede voltear de un lado para otro, y a la hora de que el mundo se voltea, los pies descubren que eran la cabeza y la cabeza se da cuenta que nunca dejó de ser un pie... ${ }^{32}$

Por lo tanto, la sociedad, junto con un Estado que responda a sus intereses colectivos, definirían el rumbo nacional de los recursos - no sólo bióticos-, haciendo frente y desplazando a las oligarquías nacionales y a las estructuras de poder de los estados nacionales hegemónicos y sus CMN. Tal sería el fundamento de la resistencia en el plano regional e internacional.

\section{CONCLUSIÓN}

Los argumentos antes mencionados son resultado de la irreductible diversidad biológica y cultural del mundo, como límites a un sistema que ha creado

31 Me refiero a todos los sujetos desposeídos de medios de producción y que por lo tanto, bajo su calidad de asalariado - sea de cualquier nivel- y desempleado (ejército industrial en activo y de reserva, respectivamente), compone lo que en la teoría marxista se conceptualiza como clase proletaria o sujeto social proletario.

32 Subcomandante Marcos (principal representante del movimiento zapatista en Chiapas, México). Entrevista que sostuvo con el periodista Julio Scherer García y transmitida por Televisa el día sábado 10 de marzo de 2001. Para consulta hemerográfica ver "Jamás cederemos en las tres condiciones para dialogar: Marcos”, La Jornada, 11 de marzo de 2001, p. 6. Para información sobre el movimiento zapatista véase: <www.ezln.org>. 
riqueza, pero también miseria (objetiva y subjetiva), y que nos lleva a buscar en contracorriente una alternativa. Así, la salida estaría en articular leyes, códigos y biodiversidad viviente, BsG y ecosistemas, saberes locales y formales; pero por encima de todo, colocando como punto clave de partida al territorio concreto, pues en última instancia la biodiversidad se pierde in situ y se restituye in situ. El proceso empieza y termina en el ecosistema, donde el eje articulador no está en el capital sino en la capacidad autogestiva de la nación, y entonces de sus comunidades, hecho que implica de entrada una nueva racionalidad ecológica, con nuevas formas de acceso, propiedad, uso y manejo de los recursos bióticos.

\section{BIBLIOGRAFÍA}

- American Journal of Tropical Medicine Hygiene, vol. 52, núm. 2, febrero de 1995, pp. 155-158.

- Banco Mundial, Mesoamerican Biological Corredor Project, reporte núm. 23132-ME, 6 de noviembre de 2000. Disponible en internet: <www.gef.org>.

- Barreda Marín, Andrés (1999), Atlas geoeconómico y geopolítico del estado de Chiapas, Tesis de doctorado en Estudios Latinoamericanos, México, FCPyS, UNAM.

- Bartra, Armando (2000), "La renta de la vida", suplemento Ojarasca, en La Jornada, México, octubre, pp. 3-4.

- Berlin, Brent y Ann Louis Berlin (1996), Medical Ethnobiology of Highland Maya of Chiapas, México, Princeton University Press.

- Berlin, Brent, "Etnobotánica médica y desarrollo sustentable: el caso del ICGB-Maya en los Altos de Chiapas", ponencia del 30 de junio de 2000, UAMIztapalapa, México, D.F.

- Casifop/ETC Group (antes RAFI) (2000), Biopiratería en México: la punta del iceberg, septiembre.

- Castillo, Antonio, "Las áreas naturales: ¿protegidas?", en La Jornada, México, 15 de enero de 2000.

- CI (1999), 1999 Anual Report, Nueva York.

- Dawkins, Kristin (1997), Gene Wars: the Politics of Biotechnology, The Open Media Pamphlet Series, Nueva York.

- Delgado Ramos, Gian Carlo (2001), El carácter geoeconómico y geopolítico de la biotecnología, Tesis de licenciatura en Economía, México, Facultad de Economía-UnAM.

- Delgado Ramos, Gian Carlo (2000), "La biodiversidad como materia prima del desarrollo de la biotecnología y la piratería del conocimiento indígena”, 
en suplemento La Jornada del campo, en La Jornada, México, 10 de abril de 2000, pp. 6-7.

- Departamento de Agricultura de la Universidad de Arizona: $<$ http://ag.arizona.edu/OALS/ICBG/reports/1998winter.html>.

- Doremus, Seller, Pauly y Reichn (1998), The Myth Of the Global Corporation, New Jersey, Princeton University Press, pp. 12-20.

- Graham S. Pearson (1998), "The Threat of Deliberate Disease in the 21st. Century", en Henry L. Stimson Centre, Biological Weapons Proliferation: Reasons for Concern, Courses of Action, Report num. 24, enero, pp. 5-8.

- Harmon, David (1996), "Losing Species, Losing Languages: Connections Between Biological and Linguistic Diversity", Southwest Journal of Linguistics, núm. 15, Special Issue: Language Loss and Public Policy II, Garland D. Bills Editor, pp. 89-108.

- Instituto Nacional Indigenista (INI) y Comisión Nacional para el Conocimiento y Uso de la Biodiversidad (Conabio) (1999), "Pueblos indios, biodiversidad y política ambiental”, México, disco compacto.

- Japanesse Journal of Cancer Research, vol. 84, núm. 12, diciembre de 1993, pp. 1215-1218.

- Japanesse Neurology Science, vol. 87, núm. 1, octubre de 1988, pp. 121-138.

- Lara, Lucio (1998), Etnobiología de la flora alimentaria, México.

- Mittermeier y Goettsch (1992), "La importancia de la diversidad biológica de México", en Conabio, México ante los retos de la biodiversidad, México.

- Mooney, Pat, ETC Century, RAFI (1999), <www.rafi.org>.

- Myers y Mittermeir-Goettsch y Gil (1998), MEGADIVERSITY, Cemex/CI.

- - - (2000), hotspots, Cemex/CI.

- Nadal, Alejandro (2000), "El caso del maíz mexicano en el NAFTA, variabilidad genética y liberalización comercial”, Biodiversidad, Montevideo, julio.

- Minagawa, Yoshida, Itoyama Mora, Albert y Mori, "Neutralizing Antibodies Against HTLV-1 in HTLV-1 Associated Myelopathy Tropical Spastic Paraparesis (HAM/TSP) Patients and Asymptomatic Carriers", Neurology, vol. 42, núm. 11, noviembre de 1992, pp. 2210-2212.

- Proc. National Academic Science, vol. 91, núm. 3, febrero de 1994, pp. 11241127.

- "Protegerán México y siete países $768 \mathrm{mil} \mathrm{km} \mathrm{de} \mathrm{bosques} \mathrm{y} \mathrm{selvas/El} \mathrm{pro-}$ yecto del Corredor Biológico Mesoamericano, una acción común entre los países que lo conforman", La Jornada, 18 de octubre de 2000, p. 46.

- RAFI (1996a), "Nuevas interrogantes acerca del manejo e intercambio de tejido humano en los institutos nacionales de salud de los Estados Unidos (NIH)", en RAFI Comuniqué, marzo-abril. 
- RAFI (1996b), "Empresas farmacéuticas hacen ofertas por las colecciones de los jardines botánicos del norte en un intento de eludir la Convención de Biodiversidad", en RAFI Communiqué, julio-agosto.

- RAFI (1999), Gene Giants, Masters of universe?, abril.

- Ramamoorthy, T.P., Robert Bye, A. Lot y J. Fa (1993), Biological Diversity of México. Origins and Distributions, Oxford University Press, Oxford.

- Robbins-Roth, Cynthia (2000), From Alchemy to Ipo, The Business of Biotechnology, Massachusetts, Estados Unidos, Perseus Publishing, pp. 97-104.

- Rodríguez, Silvia y Grain (2000), "Biodiversidad y los derechos de protección vegetal”, en Biodiversidad, sustento y culturas, Grain, marzo.

- Saxe-Fernández, John (2000), "Globalización, poder y educación pública”, en Estado, universidad y sociedad: entre la globalización y la democratización, tomo I, colección Educación Superior, México, Encuentro de Especialistas en Educación Superior, Centro de Investigaciones Interdisciplinarias en Ciencias y Humanidades, UNAM.

- Thompson y Hirst (2000), Globalization in Question, Londres, Polity Press, pp. 2-12.

- Toledo, Víctor Manuel (2000), "Indigenous Peoples and Biodiversity", en Enciclopedia of Biodiversity, vol. 1, Academic Press, pp. 1181-1211.

- Veraza, Jorge (1984), "Karl Marx y la técnica: desde la perspectiva de la vida", en Críticas de la Economía Política, edición latinoamericana, núm. 22/23, México.

- William K., Tabb (1997), "Globalization is an Issue, The Power of Capital is the Issue”, en Monthly Review, vol. 49, núm. 2, Nueva York, junio.

Problemas del Desarrollo, vol. 32, núm. 126 , 